\title{
PERCURSOS METODOLÓGICOS PARA A APREENSÃO DE UNIVERSOS DE ADOLESCENTES E JOVENS: UM ENFOQUE SOBRE A QUESTÃO DAS DROGAS*
}

\author{
METHODOLOGICAL ROUTES TO APPREHEND UNIVERSES OF \\ ADOLESCENTS AND YOUNGSTERS: A FOCUS ON THE DRUG ISSUE
}

\author{
Paulo Estevão Pereira' ${ }^{1}$, Ana Paula Serrata Malfitano²
}

\section{RESUMO:}

Introdução: o tema drogas vem ganhando relevância especialmente em relação às juventudes pobres, identificadas como em maior vulnerabilidade a esta questão. No entanto, ações propostas, especialmente pelos serviços de saúde, têm se mostrado limitadas em atender a demandas específicas dessa população, traduzindo-se na baixa adesão aos serviços. Decorre de que o emprego de metodologias de pesquisa baseadas apenas em dados clínicos, estatísticos e/ou epidemiológicos, no estudo das juventudes pobres, não é suficiente para apreender os contextos sociais diversos, suas vivências singulares, tampouco sua compreensão acerca dos fenômenos que vivem, exigindo metodologias mais apropriadas. Objetivo: discutir o uso de metodologias de pesquisa participativas na apreensão dos universos juvenis. Método: utilizou-se dados de uma pesquisa qualitativa entre jovens pobres, frequentadores de um Centro da Juventude, no interior do Estado de São Paulo, empregando como recursos metodológicos: observação participante durante nove meses; entrevistas com nove jovens, ambos os sexos, entre 15 e 29 anos, e realização de oficinas de atividades, com as temáticas da pesquisa. As contribuições da Terapia Ocupacional Social constituíram o embasamento teórico do estudo. Resultados: o emprego de metodologias participativas na apreensão do universo dos sujeitos estudados nos permitiu acessar conteúdos e significados sobre a visão deles acerca das drogas. Discussão: a temática das drogas e sua inserção no cotidiano de jovens pobres aparecem carregadas de nuances não percebidas, ou não acessadas pelos serviços, levando-nos a considerar a necessidade de apreender a experiência juvenil de uma perspectiva ampliada, se quisermos fazer frente a tais questões.

Palavras-chave: adolescente; terapia ocupacional; pesquisa qualitativa; métodos.

\section{ABSTRACT:}

Introduction: The drug issue has been gaining importance especially with respect to deprived youths, identified as very vulnerable to this matter. However, actions proposed, mostly by health services, have not been able to meet the specific demands of this population, leading to low adherence to services. It turns out that the application of research methodologies based only on clinical, statistical and/or epidemiological data, in the study of poor youths, is not enough to apprehend the diverse social contexts, their singular experiences, either their understanding of these phenomena, requiring most appropriate methods. Objective: Discuss the use of participatory research methodologies to apprehend youth universes. Methods: Data from a qualitative research among poor youngsters who attend a Youth Center ("Centro da Juventude") in a midsize city of the State of Sao Paulo were used, applying the following methodological resources: participatory observation for nine months; interviews with nine youngsters - young men and women, aged 15 to 29; and workshops on the research themes. The contributions of Social Occupational Therapy were the theoretical framework for this study. Results: The application of participatory methodologies to apprehend people's universes allowed for the access of contents and meanings about their perceptions on drugs. Discussion: The theme of drugs and its insertion in the lives of these deprived youngsters emerged full of nuances not yet perceived or accessed by health services. Therefore, it is worth considering the necessity to apprehend the youth experience in an expanded perspective, if these issues are to be faced.

Key words: adolescent; occupational therapy; qualitative research; methods.

* Este trabalho recebeu apoio da Coordenação de Aperfeiçoamento de Pessoal de Nível Superior - CAPES, por meio do Programa de Reestruturação e Expansão das Universidades Federais (REUNI).

1 Terapeuta ocupacional, Especialista em Saúde Pública com ênfase em Saúde Mental pela Universidade Estadual de Campinas (UNICAMP), mestre em Terapia Ocupacional pelo Programa de Pós-Graduação em Terapia Ocupacional da Universidade Federal de São Carlos (UFSCar), bolsista CAPESReUni.

2 Terapeuta Ocupacional, Doutora em Saúde Pública pela Universidade de São Paulo, Professora Adjunta do Departamento de Terapia Ocupacional e do Programa de Pós-Graduação em Terapia Ocupacional da UFSCar. Corresponding author: estevao.paulo@gmail.com

Suggested citation: Pereira PE, Malfitano APS. Methodological routes to apprehend universes of adolescents and youngsters: a focus on the drug issue. J. Hum. Growth Dev. 2012; 22(3): 334-340

Manuscript submitted Jan 20 2012, accepted for publication Aug 102012. 


\section{INTRODUÇÃO}

O conceito de juventude é fruto de uma construção social ${ }^{1-3}$ e, como tal, sujeito a estereótipos, a momentos históricos específicos, definido a partir de múltiplas referências e determinado a partir de diferentes e diversificadas situações como gênero, classe, etnia ou grupo ${ }^{1}$.

Tal diversidade de olhares sobre essa parcela da população resulta em múltiplas propostas de delimitá-la ou classificá-la, sejam por faixa etária (no Brasil adota-se o intervalo entre 15 e 29 anos $^{4}$ ), aspectos psicológicos ou biológicos (maturidade/ imaturidade), critérios socioeconômicos (renda, escolarização, casamento, paternidade, maternidade, ambiente rural ou urbano e independência econômica) ou estado de espírito, estilo de vida ou setor da cultura².

Essa multiplicidade de abordagens sobre um mesmo recorte populacional reforça a condição dinâmica e de permanente evolução/involução da juventude enquanto conceito ${ }^{3}$ não sendo possível pensá-la como um contínuo temporal e a-histórico ${ }^{5}$. Além disso, vem refletir a complexidade e a intensidade das questões sociais suscitadas por esta que tem sido a parcela da população depositária tanto das esperanças de um futuro melhor, quando da responsabilidade pelos descaminhos da sociedade ${ }^{6}$.

Nessa perspectiva, deve-se abordar a experiência juvenil sob dois aspectos: a condição juvenil e a situação social do jovem ${ }^{7,3}$. A primeira, enquanto categoria sociológica e antropológica, refere-se aos valores e à cultura particular dos sujeitos jovens. A segunda, mais singular, remete às maneiras como os sujeitos experienciam sua condição de jovens num determinado espaço e tempo ${ }^{3}$.

Dessa forma, existem diferentes maneiras de se vivenciar a juventude a depender do contexto social, histórico, econômico, político; do gênero, classe social, etnia, local de residência (rural ou urbana, no centro ou na periferia), etc. Ainda que se possa delimitar de certa forma a condição juvenil, a situação de ser jovem requer a pluralização ${ }^{3}$ nos discursos e ações, para que não se corra o risco da geração de "pontos cegos" ao se abordar esse universo. Assim, a questão do jovem e das juventudes, com todos os seus dilemas, tem aparecido nos últimos anos como uma questão social ${ }^{8}$ a ser atendida pelas políticas públicas.

Sob essa perspectiva, o que temos é que a situação dos jovens em nossa sociedade, em especial aqueles provenientes das camadas populares, tem assumido um discurso de grupo de risco, como um desafio à integridade do tecido social. Se por um lado são cobrados como o "futuro da nação"2, ao mesmo tempo, dentro da lógica da crise da sociedade salarial e do aumento das zonas de vulnerabilidade devido à precarização social ${ }^{8}$, são impedidos do acesso a bens culturais e materiais, ao trabalho e à educação de qualidade, gerando uma enorme massa de desfiliados ${ }^{8}$, com todas as problemáticas decorrentes dessa condição.
Cria-se, então, um "discurso esquizofrênico"5 em torno da juventude, que tem gerado uma série de incertezas e contribuído para o aumento das vulnerabilidades a que estão sujeitos.

Dentro do panorama contemporâneo, jovens residentes nas áreas precarizadas das cidades, com dificuldade de acesso à cultura, ao lazer, diminuídos de poder de troca, afastados das instituições sociais e dos bens de consumo, numa sociedade consumista, acabam encontrando filiação e pertencimento em outras estruturas sociais ditas marginais (ou marginalizadas), desenvolvendo sociabilidades e formas de produção e reprodução de vida que reforçam um imaginário social que lhes atribui uma visão negativa.

Se acrescentarmos o fenômeno da drogadição à discussão sobre a categoria juventude, a carga que recai sobre os jovens pobres aumenta consideravelmente, uma vez que a associação entre os elementos pobreza e drogas aparece quase como "natural" no imaginário social. Em resposta a tais questões, a sociedade tem agido através de suas instituições, mormente por meio da saúde, com a tendência a medicalizar os objetos de suas intervenções ${ }^{9,10,11}$.

O Ministério da Saúde, em documento no qual institui a Política Nacional para Atenção Integral a Usuários de Álcool e outras Drogas, assume a questão da drogadição como problema de saúde pública e toma para si as ações institucionais e da sociedade civil a esse respeito ${ }^{12}$. Quanto à oferta de atendimento, o documento estabelece uma consonância com a Política de Saúde Mental vigente, regulamentada e respaldada na Lei 10.216 , de 06/ 04/2001 12 , baseada nos Centros de Atenção Psicossocial (CAPS), articulados à rede assistencial em saúde mental e ao restante da rede de saúde, atuando sob a lógica do território e procurando considerar as necessidades e demandas específicas da clientela ${ }^{12}$.

Entretanto, faz-se necessário discutir, para além da composição de uma rede de atendimento, os elementos que circundam a questão e sua complexidade social, no envolvimento de aspectos da vida cotidiana de tais grupos. Nessa direção, estudos têm apontado que os serviços de saúde não têm ofertado atendimento adequado ao jovem ou não estão preparados para atendê-los adequadamente ${ }^{13,14,15}$. Dessa forma, existe a necessidade de criar âmbitos específicos de planejamento e discussão para eles, de modo a garantir e respeitar suas especificidades ${ }^{15}$. No âmbito da Reforma Psiquiátrica, diretrizes e estratégias de atenção elaboradas de acordo com uma visão mais geral do tema acabam dificultando que suas demandas singulares sejam devidamente consideradas ${ }^{15}$. Nessa perspectiva, estudos apontam que os CAPS no país não contemplam ainda a questão da juventude de uma forma diferenciada, não levando em consideração as especificidades dessa população ${ }^{13}$.

A literatura tem apontado que, em relação à população de jovens usuários de substâncias psicoativas, o índice de adesão aos tratamentos 
oferecidos é mais baixo que aquele entre os usuários em geral ${ }^{14,16}$ e que tal fato pode ser explicado tanto por fatores ligados à própria dinâmica juvenil, uma vez que poucos buscam ajuda por conta própria e dificilmente relacionam seus problemas ao uso de substâncias ${ }^{16}$, quanto pela inadequação e despreparo dos serviços para atender a essa população específica ${ }^{14}$. Acrescentaríamos à questão o fato de haver uma superficial reflexão acerca da dinâmica do uso de drogas por essa população, partindo da tentativa de explicações apenas contextualizadas à esfera clínica que, embora necessárias, distanciam-se das múltiplas vertentes sociais que acompanham o uso de drogas por jovens contemporaneamente.

O predomínio do "modelo de doença" nos tratamentos desenvolvidos pode levar a uma ênfase excessiva na questão da dependência em detrimento das "motivações inconscientes dos sujeitos, assim como o papel do meio social na instalação das dependências"17. Aponta-se ainda que o foco da atenção oferecida recai fortemente na visão do jovem como "problema social", culpabilizando-o pelas demandas sociais que incidem sobre ele próprio ${ }^{15}$.

Sob esse ponto de vista, discute-se que para oferecer respostas a problemáticas sociais contemporâneas, como o fenômeno das drogas, não bastam os recursos da clínica, bem como não são suficientes a produção de dados epidemiológicos ${ }^{3,13}$. É necessário lançar mão de novas tecnologias sociais que sejam capazes de abarcar a temática de forma ampliada, em toda sua complexidade, incluindo o desenvolvimento de tecnologias sociais que propiciem a escuta da população-alvo acerca de si mesma e sua relação com as drogas.

No entanto, aproximar-se de fato do universo juvenil e poder verdadeiramente dar escuta às suas perspectivas, exige uma mudança na forma de interagir com esse universo e seus atores. É preciso abandonar os discursos construídos "sobre" eles e construir um novo, "com" eles. Um segundo aspecto a se considerar está na própria natureza do tema das drogas, marcada por interdições (veladas ou explícitas), alvo de discursos de variados matizes, que têm animado discussões acadêmicas, políticas e da sociedade civil.

Pela complexidade da temática, faz-se necessário o emprego de metodologias participativas e o estabelecimento de vínculos entre pesquisador e atores, construindo uma interação mais democrática do ponto de vista dos saberes, requerendo que o pesquisador abandone seu posto de saber instituído e se disponha a aprender e apreender a realidade a partir do saber do outro, tecendo estratégias fundamentais para abordar questões como as que nos propusemos.

Como auxílio para tais desafios, apoiamo-nos nos pressupostos da Terapia Ocupacional Social a qual, na medida em que busca uma atuação direta sobre o campo social ${ }^{18,19}$, procura compreender as interações sociais que atuam sobre os sujeitos, determinando variadas formas e intensidades de dissolução de vínculos, de vulnerabilização das redes sociais e precarização do trabalho ${ }^{20}$, de modo a atuar com os sujeitos e levá-los a se apropriarem de suas realidades, encontrando maneiras, quando possível, de transformá-la e tornarem-se co-responsáveis pelas mudanças sociais necessárias.

Nessa perspectiva, as ações da terapia ocupacional no campo social visam à autonomia e cidadania dos sujeitos, por meio da intervenção em seu cotidiano, na tentativa de promover mudanças $^{18}$, sempre contextualizadas aos limites da realidade altamente desigual. Para tanto, é preciso compreender a complexidade das relações sociais a partir da leitura que os atores fazem delas, identificando e reconhecendo as experiências singulares de tais atores, bem como as representações que fazem de suas experiências ${ }^{19}$.

\section{MÉTODO}

Foi empreendida uma pesquisa qualitativa junto a jovens entre 15 e 29 anos, residentes na periferia de uma cidade de médio porte no interior do Estado de São Paulo, e que frequentavam um "Centro da Juventude" (C.J.) municipal, destinado ao desenvolvimento de ações ligadas à cultura, ao lazer e ao esporte. A escolha daquele território, entendido não apenas como delimitação geográfica, mas pressupondo, também, sua constituição histórica e as relações socioeconômicas e culturais ali desenvolvidas ${ }^{21}$, deveu-se a uma estratégia de pesquisa que buscava permitir uma maior diversidade dos sujeitos em relação à questão das drogas, evitando-se recortes a partir das abordagens da saúde (como os Centros de Atenção Psicossociais para usuários de álcool e outras drogas - CAPS-ad) e da justiça (adolescentes em cumprimento de medidas sócio-educativas ou em instituições educativas em decorrência do ato infracional).

Nossa entrada no campo de pesquisa tornouse viável mediante a inserção nas atividades desenvolvidas na região desde 2005 pelo Núcleo UFSCar do Projeto METUIA, grupo interinstitucional de pesquisas e ações em Terapia Ocupacional Social, agregando estudantes, pesquisadores e técnicos, vinculados à Universidade de São Paulo e à Universidade Federal de São Carlos ${ }^{22}$.

Assim, partindo do referencial teórico da Terapia Ocupacional Social, os recursos metodológicos de que nos servimos para acessar os sujeitos do estudo foram: observação participante, realizada por um período de nove meses, duas vezes por semana, a partir do acompanhamento de oficinas de atividades de convivência; redação de diários de campo, compostos durante o processo; entrevistas semidirigidas com os jovens e oficinas de atividades, estruturadas por temática (identidade, cotidiano e drogas).

A observação participante tem como principal aspecto o fato de o pesquisador "mergulhar de cabeça no campo"23, e tanto observar de uma pers- 
pectiva como membro, quanto influenciar o que é observado devido à sua participação no local. Ao favorecer ao pesquisador maior tempo em contato com as pessoas e contextos que observa, é possível desenvolver a pesquisa como um processo que se ajusta em conformidade com as manifestações do próprio campo, permitindo ao pesquisador maior flexibilidade e apropriabilidade metodológicas na condução da mesma²3.

No decorrer das interações, nossas observações e percepções pessoais eram registradas em diários de campo que se constituíram em importante fonte de reflexão e base para as interpretações que empreendemos.

Porém, nem todos os fenômenos de um campo de estudo podem ser observados, de modo que a observação participante em si não favorece a captura de processos biográficos e de eventos que ocorram raramente ${ }^{23}$. Daí a importância de se somar à observação as entrevistas com os participantes, de modo a apreender aspectos da realidade que poderão ser acessíveis a partir dos relatos verbais dos sujeitos ${ }^{23}$.

Para tanto, propusemos a realização de entrevistas semidirigidas junto a nove jovens com os quais nos vinculamos no período da observação, sendo sete do sexo masculino e duas do sexo feminino, com média de idade de 17 anos. O roteiro de entrevistas, aplicado não de forma sequencial, mas como um norteador dos assuntos abordados, foi composto com base nas questões levantadas pela revisão bibliográfica realizada sobre a temática juventudes pobres e drogas, e procurou abarcar as questões inerentes ao ser jovem na periferia, seu cotidiano, a forma como as drogas aparecem no seu dia-a-dia e a sua percepção sobre o fenômeno.

Todos os aspectos éticos relacionados aos procedimentos de pesquisa foram observados, de modo a garantir aos entrevistados a confidencialidade das respostas, preservando suas identidades, acesso às informações relativas ao estudo e deixando explícito para os participantes o total controle quanto à sua participação ou não na pesquisa. Havendo o aceite para colaborar com a pesquisa, os participantes recebiam e assinavam o Termo de Consentimento Livre e Esclarecido.

A fim de obter uma perspectiva mais abrangente da temática em questão, lançamos mão, como recurso metodológico de coleta de dados, da realização de Oficinas de Atividades, compreendidas como espaços de experimentação, aprendizagem e expressão livre, na qual os participantes são percebidos como seres ativos no processo de construção de si mesmos, possibilitando a vivência de experiências democráticas e igualitárias na interação com outros sujeitos ${ }^{24}$.

Dentro da perspectiva da Terapia Ocupacional, nossa formação de base, as atividades humanas se constituem no elemento centralizador das práticas profissionais, justamente pelo caráter organizador e estruturador da vida cotidiana desempenhado por elas ${ }^{25}$.
Isto posto, ao abordarmos as questões de pesquisa por meio do "fazer" dos jovens (complementando o que acessamos pelo "dizer" deles), buscamos a possibilidade de apreender as percepções e concepções dos participantes frente às temáticas propostas (identidade juvenil, cotidiano na periferia e drogas), com o intuito de nos aproximar da visão deles sobre suas próprias vivências.

\section{RESULTADOS}

A composição dos dados de pesquisa por meio dessa teia de recursos metodológicos, todos baseados na interação e participação ativa, tanto dos sujeitos quanto nossa, nos permitiu compor um panorama do universo onde se inserem aqueles jovens e as diversas formas com que a temática das drogas aparece no seu cotidiano. Dados quantitativos, ainda que de grande importância para apontar eventos gerais, são insuficientes para captar as nuances e singularidades da experiência cotidiana. Dessa forma, ações direcionadas ao público jovem baseadas em dados clínicos, estatísticos e/ou epidemiológicos, na maior parte das vezes, não acessam as especificidades dessa população, em especial no que tange aos jovens das camadas populares ${ }^{3}$.

Assim, o fenômeno das drogas, tanto em relação ao uso quanto ao comércio, aparece na vida daqueles jovens de maneira constante e carregada de ambiguidades. A temática está presente nas relações de amizade, de parentesco, nos modos de organização da coletividade, nos "códigos" de conduta adotados e reafirmados cotidianamente. Tais aspectos dificilmente poderiam ser acessados sem uma permanência mais direta no território, sem um contato com os jovens numa relação de horizontalidade e proximidade, apreendendo a questão a partir dos seus olhares. O que procuramos afirmar é que os aspectos que compõem a relação complexa entre o fenômeno das drogas e o cotidiano de jovens pobres não podem ser devidamente apreendidos a partir de settings terapêuticos ou institucionais, nem por meio de metodologias mais diretas ou diretivas.

J. - Ah, eu vejo bastante, de crianças assim, já... fumando...bebendo, fazendo essas coisa errada, mas... Não aparece ali do nada, né? Porque eles oferece e também as pessoa não fuma escondido, fuma na vista de todo mundo... Aí tem criança que vê e quer fazer a mesma coisa. Aí vai, fazendo assim, vai indo até...

Pergunta- E isso você vê nos lugares que você frequenta, mais próximo da sua casa, como é? J.- Mais próximo da minha casa. Tem vários lugares que vendem. Principalmente na casa da minha tia vende. Ela tem bastante criança. Aí eu penso no futuro deles, né? Eles convivem lá! Aí...

J., masculino, 16 anos.

A convivência próxima com a temática das drogas, dentro das famílias ou na porta de suas 
casas, evidencia o grau de vulnerabilidade a que estão expostos aqueles jovens. No entanto, as representações que essa convivência assume para os sujeitos muitas vezes se mostram ambíguas, indo além do julgamento moral. Vejamos o que o mesmo J. nos diz a respeito.

Pergunta- E o que você acha disso [seus tios venderem drogas]?

J. - Ah, eu acho que não é muito bom porque... arrisca a vida deles, né? Já tem três filhos que já foram presos. Só que eles não pensa na hora e todo mundo... Sabe, depois que foi lá dentro [preso] e sai, aí quer voltar, aí já é tarde, né! Só que nós não fala nada, porque falar é a mesma coisa que não ter falado nada. Então...

As preocupações desse jovem não recaem sobre as atividades de seus parentes por si mesmas, mas sim em relação às consequências dessas atividades. Transparece da fala uma relação com a temática enquanto "opção de vida", respeitada, embora não tenha a concordância do jovem. Essa é uma nuance importante de se ressaltar.

Nossa presença no território e a interação cotidiana com os jovens nos permitiram acessar as explicações práticas de que se utilizam para justificar ou tornar inteligíveis, para si mesmos e para os outros, a presença do tráfico e do consumo de drogas no seu dia-a-dia. O acesso às explicações, ainda que restrito às vivências singulares dos jovens estudados nos permite captar a questão de uma perspectiva diferente da habitual.

E também, vai vendo, é isso aí. Vai procurar emprego e não consegue, aí bate o desespero e fala: "Não, preciso fazer alguma coisa! Vou vender droga! Tem droga pra mim vender?" Aí o cara fala: "Tem! Tó!" Aí o cara vai lá, ganha 100 Real num dia, cada dois dia! Aí ele vai gostando, vai gostando, começa a comprar as coisa, umas roupas... E fala: "Tô mais bonito! Tô mais respeitado!" Por causa da droga. Aí vai! Vai indo até chegar no alto! Aí é complicado!

$$
\text { C., masculino, } 22 \text { anos }
$$

Pergunta- E porque você acha que as pessoas escolhem esse tipo de trabalho?

G. - [Silêncio] Porque é o jeito mais fácil de ganhar dinheiro, né? Sem esforço. O mais fácil eles escolhem, né? Mais fácil do que estudar, trabalhar todo dia [pausa] Daí a um minuto ele já tem o dinheiro ali, né? É isso!

$$
\text { G., feminino, } 17 \text { anos }
$$

Pergunta- E você acha que as pessoas escolhem esse tipo de trabalho por quê?

F.- Não, uns não têm opção, né? Mas outros também que, o dinheiro é fácil, vê que é fácil... "Ah, não! vai só um dia!" Aí depois acostuma, não quer mais sair! Aí, já era!

Pergunta- Então, falta oportunidade?

F.- Mas alguns não! Alguns têm oportunidade, tem família boa, pai trabalha, mãe trabalha, mas quer ficar nessa vida aí!

F., masculino, 15 anos
Esses enunciados coexistem no universo relacional daqueles jovens, expressando maneiras pelas quais os sujeitos buscam tornar explicáveis para si mesmos a realidade onde se inserem.

A imersão no universo da pesquisa permitiu a apreensão de modos de funcionamento da coletividade, de regras de conduta e convivência que estruturam o cotidiano daquelas pessoas. Permitiu compreender como se estabelecem as sociabilidades e como são construídas as subjetividades naquele espaço social. Dois trechos retirados dos nossos diários de campo ilustram tal ideia.

Acompanhado das estagiárias do METUIA e de C., morador do bairro, fazemos uma incursão pelo bairro, para conhecer o território. C. é nosso guia. Vai nos apresentando o ambiente, os problemas que enfrentam e os modos de funcionamento da comunidade. Discretamente, aponta uma determinada pessoa e nos explica, cuidadosamente, que 'aquele mais outros' são os responsáveis por manter a ordem no bairro. 'Porque aqui nós não pode chamar a polícia', conta C. 'São eles que resolve as diferença entre os moradores por aqui'.

Diário de Campo, 23/07/2010

É a terceira visita ao C.J. , desde o encerramento das atividades do METUIA, em 25/11, na tentativa de contatar alguns dos jovens que entrevistamos, para, em parte, solucionar questões surgidas no campo, em parte para revê-los. Porém, os jovens não vêm frequentando o C.J. há mais ou menos um mês, segundo apurei com os funcionários. Combinei com a coordenação do C.J. de auxiliá-las na atividade de divulgação da abertura de uma sala do EJA (Educação de Jovens e Adultos), $5^{a}$. série, no C.J., numa incursão "corpo a corpo" pelo bairro. O plano era a distribuição de panfletos nas casas e às pessoas e a colocação de cartazes em locais de maior circulação. Pensei em aproveitar essa incursão na companhia das funcionárias e tentar o contato com os jovens. Nos reunimos em frente ao C.J. dividimos o material e descemos ao [bairro]. Fiquei surpreso com a apreensão das funcionárias ao adentrar o bairro. Pensava que, por serem conhecidas e conhecerem os moradores, em especial os jovens, sua circulação fosse mais "natural". Ao contrário, a coordenadora decidiu que só percorreríamos as ruas mais no começo do bairro, não descendo em direção ao centro. Nesse percurso, pudemos observar as "atividades" do tráfico. Eram oito horas da manhã e identificamos pessoas "negociando" junto a um carro. Algumas "biqueiras" [pontos de venda de droga] já mostravam atividade. A estratégia adotada era a abordagem direta aos moradores, o mais objetiva possível, entregando os panfletos e já explicando o motivo de nossa ida até o bairro. Ninguém circula no bairro sem motivo. Na medida em que andávamos, as ruas, à princípio com poucas pessoas, foram recebendo moradores, a maioria jovens, mas não só. A cada esquina por que passávamos, moradores iam se aglomerando, "conferindo" nossa presença, "dominando" o território. Jovens se agrupavam, al- 
guns gritavam o nome uns dos outros seguidos de expressões como "É nóis! É nóis!"

Diário de campo 03 /02/2011

Outra nuance evidenciada nesse processo refere-se aos limites estabelecidos entre os que são membros daquela coletividade e os que vêm de fora. O que pode ser dito e o que só interessa a quem pertence àquele local. Embora tenhamos acessado conteúdos importantes sobre esse universo, muitas coisas nos foram veladas, por não fazermos parte daquele contexto. Trata-se, sem dúvida, de uma limitação da pesquisa, porém explicada e justificada pelas escolhas metodológicas que fizemos.

R.- Então, a gente vê, assim, porque a gente vê, assim, a gente não pode falar nada. Não pode falar nada! Então, tem uma coisa que eu aprendi, sempre meu pai fala pra mim, se você vê uma coisa, se você vê alguma coisa de errado, você não fala nada! Faz de conta que não viu nada! Então, quer dizer, ali embaixo [no bairro] eu conheço todo mundo, conheço os rapaz aí que mexe com essas parada aí, conheço todo mundo aí, então, eles me respeita, eu respeito eles, então, é, o meu dia a dia é esse.

Pergunta- E o seu pai te deu esse conselho de, se vir coisa errada não falar nada, por quê?

R.- Ele não quer ver eu... quer dizer, ele não quer o mal de ninguém, o mal dos meus colega e nem o meu também, né? Porque tem neguinho que tá começando, mas é isso, você fala uma coisinha de errado, você acaba prejudicando a você mesmo. Então, tem que pensar duas vezes do que falar.

R., masculino, 24 anos

Contudo, para além das questões suscitadas e das relações estabelecidas com e através da temática das drogas, outras preocupações dos jovens puderam ser evidenciadas, apontando necessidades que muitas vezes não são percebidas pelas políticas públicas voltadas a eles.

Pergunta- E como você enxerga seu futuro?

C.- O meu futuro me preocupa, porque arrumar serviço tá complicado. Eu vou fazer 23 anos agora. Então, eu queria tá com 21 anos e já não tá morando mais com a minha mãe. Não que eu não queira ficar com a minha mãe, mas com minha mulher e tal... Aí é complicado, né? E eu já tenho um pouco de experiência. Eu trabalhei, fiz "bico" em vários lugares. Sempre que tem "bico" eu faço. Já trabalhei em [instalação de] piscina, servente [de pedreiro], de açougueiro e fábrica de bloco. Em vários lugares, nós entrega currículo pra mercado, essas coisas, mas o pessoal não..."

C, masculino, 22 anos

G.- Eu quero me formar! Não sei em quê ainda, to vendo, mas eu gosto mais, mas pretendo me formar, sim! Estudar mais! Ter um futuro melhor!

G., feminino, 17 anos

São variadas as perspectivas dos jovens que entrevistamos a respeito dos projetos futuros, so- bre o que esperar de suas vidas. Encaram cotidianamente as dificuldades de inserção no mercado de trabalho, sofrem o estigma ligado às áreas onde moram e experimentam ser jovens numa condição social precarizada, sujeitos às vulnerabilidades decorrentes dessa precarização.

Vemos acima dois jovens com perspectivas diferentes de futuro e, de certa forma, de presente.

C., 22 anos (prestes a completar 23!), pouca escolaridade (foi até a $6^{a}$. série). Numa idade em que, em especial para jovens pobres, espera-se que esteja no mercado formal de trabalho, mas cujas possibilidades de inserção vão se tornando mais restritas a determinadas colocações, pouco qualificadas, acaba vivendo num equilíbrio precário entre duas realidades. Almeja um lugar na sociedade por meio de um trabalho que Ihe permita não só reproduzir a vida, mas também a produção de outros sentidos, que lhe permita construir um futuro, mas parece ser um lugar cada vez mais distante. Ao mesmo tempo, convive com as seduções do comércio das drogas, mais inclusivo e lucrativo. Até o momento, C. tem se equilibrado nesse interstício, nessa zona neutra entre os dois lugares. Mas, até quando?

Na sequência, G., 17 anos. Trabalha durante o dia numa instituição pública e estuda à noite. Cursa o terceiro ano do ensino médio. Sonha em se formar, ainda não sabe em quê, mas é o futuro que almeja para si. Vê nos estudos a possibilidade de um futuro melhor.

G. representa outra forma de sociabilidade, pautada pelo trabalho e pelo estudo, visando à construção de um projeto de vida que Ihe garanta uma inserção social diferenciada. No seu bairro, convive com a questão das drogas, como os demais jovens moradores da periferia. Tem sua "turma" que, conforme me disse, "é mais tranquila que as outras", divertem-se indo a pizzarias, conversando na praça, saindo de vez em quando. Seu cotidiano é estruturado pelo trabalho e estudos, restando-Ihe livres os finais de semana, quando prefere ficar mais em casa.

Diferente de C., a incerteza quanto ao seu futuro reside na possibilidade de optar por uma carreira que mais lhe agrade, que Ihe satisfaça pessoal e profissionalmente. A incerteza recai sobre a existência de opções, não na falta ou escassez delas, como no caso de C. Tem a possibilidade de pensar o que vai escolher para seu futuro, enquanto que C. precisa se agarrar ao que aparecer. Frente às incertezas inerentes ao amanhã, para alguns elas são mais incertas que para outros.

O emprego de metodologias participativas na apreensão do universo dos sujeitos estudados nos permitiu acessar outros conteúdos, ligados ao cotidiano daqueles rapazes e moças.

Existe uma diferença marcante em se abordar jovens pobres como se compusessem uma categoria única, homogênea, e abordá-los a partir de suas singularidades. Cada grupo juvenil tem espe- 
cificidades que precisam ser consideradas ao se propor ações que se queiram efetivas.

Ser jovem pobre na periferia de uma metrópole certamente é diferente de o ser numa cidade do interior. As sociabilidades são distintas, as vulnerabilidades podem se apresentar de maneiras diversas. Fica evidente que as diversidades, para serem apreendidas e consideradas, requerem metodologias de acesso que sejam mais participativas, tais como as que apresentamos nesse artigo.

Nossa presença no território dos jovens estudados, buscando partilhar interações no contexto (ou em parte dele) em que se inserem nos favoreceu um olhar ampliado para a questão das drogas em relação àqueles jovens. Estar junto com eles, olhar o seu entorno a partir do olhar daqueles jovens; ouvi-los, de fato, tentando não lançar mão de noções pré-concebidas; procurar favorecer a criação de espaço para a expressão livre de suas percepções, por meio de atividades, tudo isso fez toda a diferença para uma visão mais compreensiva daquele universo e a forma como abordá-lo.

Mais do que apontam as estatísticas oficiais, os programas de combate às drogas, a mídia, a opinião pública, enfim, a questão das drogas, ainda que fortemente presente no cotidiano dos jovens que estudamos, não se constitui como o problema cen-

\section{REFERÊNCIAS}

1. Abramovay M, Esteves LCG. Juventude, juventudes: pelos outros e por elas mesmas. In: Abramovay M, Andrade, ER, Esteves LCG ,orgs. Juventudes: outros olhares sobre a diversidade. Brasília: Ministério da Educação, Secretaria de Educação Continuada, Alfabetização e Diversidade; Unesco; 2007. p.19-54.

2. Catani AM, Gilioli RSP. Culturas juvenis: múltiplos olhares. São Paulo: UNESP. Coleção Paradidáticos (Série Cultura); 2004.

3. Léon OD. Adolescência e juventude: das noções às abordagens. In: Freitas MV, org. Juventude e adolescência no Brasil: referências conceituais. São Paulo: Ação Educativa; 2005. p. 9-18.

4. Novaes RCRN, Cara DT, Silva DM, Papa FC, orgs. Política nacional de juventude: diretrizes e perspectivas. São Paulo: Conselho Nacional de Juventude; Fundação Friedrich Ebert; 2006.

5. Reguillo R. Las culturas juveniles: un campo de estúdio; breve agenda para la discución. Rev. bras. educ. 2003, maio/jun/jul/ago; 23: p.103118. DOI 10.519/s1413-24782003000200008

6. Adorno RCF. Capacitação solidária: um olhar sobre os jovens e sua vulnerabilidade social. São Paulo: AAPCS, 2001.

7. Aquino LMC. Introdução: A juventude como foco da políticas públicas. In: Castro JÁ, Aquino LMC, tral de suas vidas. Outras questões, subjacentes à temática das drogas, são reveladas a partir das interações com os jovens no seu universo. O olhar horizontalizado para o objeto de pesquisa (objeto sim, porém não objetivado, coisificado), além de enriquecer a compreensão da temática, porque construída em conjunto, favorece a proposição de ações, de políticas públicas que possam, de fato, acessar as populações a que se destinam.

Assim, a questão das drogas e sua inserção no cotidiano dos jovens estudados figura, aos nossos olhos, carregada de nuances não percebidas ou não acessadas pelas políticas públicas relativas ao tema. Questões relacionadas ao cotidiano daqueles jovens, para além da temática das drogas, emergem dos dados coletados, levando-nos a considerar, em concordância com a literatura, a necessidade de apreender a experiência juvenil de uma perspectiva ampliada, se quisermos nos aproximar efetivamente desse universo.

Por fim, fica assinalada a necessidade de uma real aproximação, convivência e compreensão desses sujeitos pelas intervenções e pesquisas direcionadas às juventudes para que, efetivamente, caminhemos para uma relação horizontal, respeitosa e efetiva, com contribuições sobre a contemporaneidade.
Andrade CC, orgs. Juventudes e políticas sociais no Brasil. Brasília: IPEA, 2009. p. 25-39.

8. Castel R As metamorfoses da questão social: uma crônica do salário. 7a edição. Petrópolis: Vozes; 2008.

9. Tesser CD, Barros NF. Medicalização social e medicina alternativa complementar: pluralização terapêutica do Sistema Único de Saúde. Rev. Saúde Pública. 2008; 42 (5): p. 914-20. DOI 10519/S0034-89102008000500018

10. César MRA. A invenção da adolescência no discurso psicopedagógico. São Paulo: UNESP; 2008.

11. Tesser CD. Medicalização social (I): o excessivo sucesso do epistemicídio moderno na saúde. Interface comum. saúde educ. 2006 jan/ jun; 9(18): p. 61-76. DOI 10.1590/S141432832006000100005

12. Brasil, Ministério da Saúde. A política do ministério da saúde para a atenção integral a usuários de álcool e outras drogas. Brasília: Ministério da Saúde; 2003.

13. Malfitano APS. A Tessitura da rede: entre pontos e espaços. Políticas e programas sociais de atenção à juventude - a situação de rua em Campinas, SP [Tese]. São Paulo. Faculdade de Saúde Pública da Universidade de São Paulo; 2008.

14. Scadutto AA, Barbieri V. O discurso sobre a adesão de adolescentes ao tratamento da dependência química em uma instituição de saúde 
pública. Ciênc. Saúde Coletiva. 2009; 14(2): p. 605-14.

15. Vicentin MCG. Infância e adolescência: uma clínica necessariamente ampliada. Rev. Ter. Ocup. da Univ. de São Paulo. 2006 jan/abr; 17(1): p. 10-17

16. Andretta I, Oliveira MS. A técnica da entrevista motivacional na adolescência, Psicol clín. 2005 17(2): p. 127-39. DOI 10.519/S010356652005000200010

17. Raupp L, Milnitsky-Sapiro C. Adolescência, drogadição e políticas públicas: recortes no contemporâneo. Estud. psicol. (Campinas) 2009, out-dez; 26 (4): p. 445-454. DOI 10.519/ S0103-166X2009000400005.

18. Malfitano APS. Campos e núcleos de intervenção na terapia ocupacional social. Rev. Ter. Ocup. Univ. de São Paulo. 2005, 16(1): p. 1-8, jan/abr.

19. Galheigo SM. O social: idas e vindas de um campo de ação em terapia ocupacional, In: Pádua EMM, Magalhães LV, orgs. Terapia Ocupacional: Teoria e Prática. 2a Ed. Campinas: Papirus; 2003.

20. Barros DD, Lopes RE, Galheigo S. Terapia ocupacional social: concepções e perspectivas. In:
Cavalcanti A, Galvão C, orgs. Terapia Ocupacional - Fundamentação e Prática. Rio de Janeiro: Guanabara Koogan; 2007. p. 347-353.

21 Oliver FC, Barros DD. Reflexionando sobre desinstitucionalización y terapia ocupacional. Materia Prima, Primera Rev. Independiente Ter. Ocup. Argentina. 1999; 4 (13): p. 17-20.

22. Barros DD, Lopes RE, Galheigo S. Novos espaços, novos sujeitos: a Terapia Ocupacional no trabalho territorial e comunitário. In: Cavalcanti A, Galvão C, orgs. Terapia Ocupacional - Fundamentação e Prática. Rio de Janeiro: Guanabara Koogan; 2007. p. 354-363.

23. Flick U. Uma introdução à pesquisa qualitativa. Trad. Sandra Netz. São Paulo: Bookman: 2004.

24. Silva CR. Oficinas, In: Park MB, Fernandes RS, Carnicel A, orgs. Palavras-chave em educação não formal. Holambra: Setembro; Campinas: UNICAMP/CMU, 2007. p. 213.

25. Castro ED, Lima EMFA, Brunello MIB. Atividades humanas e terapia ocupacional. In: De Carlo MMRP, Bartalotti CC. Terapia ocupacional no Brasil: fundamentos e perspectivas. São Paulo: Plexus; 2001. p. 41-59. 